Andrea Pető

Professor

CEU, Budapest

\title{
The absence of women in the diplomacy of Visegrad countries
}

The fact that the few candidates who competed for the title of the world's first professional female ambassador were all delegated by extraordinarily short-lived governments, and all quietly forgotten by posterity is symbolic. Among them, Alexandra Kollontai (1872-1952) representing the Soviet Union, was who made it into (some of) the official accounts as the first ever female ambassador. Kollontai served in Norway in 1923, Mexico between 1926-27 and Sweden from 1930 until 1945 as the ambassador of a country that lacked international recognition. The fate of the other three "first" female ambassadors was similar to Kollontai's. Armenian writer Diana Abgar (1859-1937) was the ambassador of the first Armenian Republic in Japan from 1918 to 1920. The Hungarian professional feminist Rózsa Schwimmer (1877-1948) served as the representative of the revolutionary Károlyi-government in Switzerland between 1918-1919. Also in Switzerland was Jadvyga Chodakauskaite-Tubeliene (1891-1998), an activist in the women's movement, who set up the Lithuanian mission in 1918-1919. In the tight grip of hegemonic powers and among geopolitical constraints, these "first" female ambassadors were also struggling with their greatest disadvantage: they were women. Kollontai as a representative of the Soviet Union excellently capitalized her sense of humor, her erudition and her polyglottism during various negotations, inspiring the movie Ninochka (1939) starring Greta Garbo. The story of these "firsts" helps us to understand why the presence of women in the diplomatic service of Visegrad Four is still so meager.

Women's participation in international relations can be seen from two angles: how women themselves became active, professional agents of diplomatic processes and on the other hand, how they turned into subjects and often victims of said processes and decisions. The predecessors of Abgar and Kollontai were women who, by their husbands' or fathers' side within the framework of drawing rooms of the privileged, used their informal power and confabulation to make diplomacy. Schwimmer and Chodakauskaite-Tubeliene represented a different modality: they entered international diplomatic circles through the internationally organized and 
institutionalized women's movement and its network. In Switzerland the Hungarian Schwimmer was deemed too much of a leftist, with the task of representing a country that at the time was battling and losing against the troupes of the Triple Entente. No wonder she had little success.

Diplomacy is an international profession which requires serious professional and linguistic training, and for the successful practice of which one should be part of the elite. During the classical era of diplomacy one could belong to the elite if one was born an aristocrat. In the modern era of diplomacy access can come through education at an elite institution. No surprise that in diplomacy, men, despite all the emancipatory struggles, most adamantly preserve their institutional privileges. If we examine the lives of these four female ambassadors, it is apparent that all received ambassadorial tasks due to the social changes after World War 1 that both destroyed and created states. No suprise either that, as a result of second wave feminism's efforts, more female ambassadors were delegated from the 1980s onwards, though these were still exceptions to the rule.

According to a research conducted in late 2014 in the Visegrad countries, during state communism between 1975 and 1989, when women's equality was nominally and officially propagated, women were seldomly delegated for ambassadorial positions. One can rightly ask if in this respect 1989 brought any change into the diplomatic services of the Visegrad countries. In principle it could have, because the previous cadres who trained mainly in Moscow were replaced by people who were well-raveled and multi-lingual. For the most part however, men were replaced by men.

According to the same 2014 research, bilateral diplomatic positions in all four Visegrad countries were occupied by men by over $80 \%$ (Czech Republic $84 \%$, Poland $86 \%$, Hungary $88 \%$, Slovakia 95\%). When it comes to international organizations, male leadership also dominates: Czech Republic $71 \%$, Poland $86 \%$, Hungary $75 \%$, Slovakia $71 \%$. Though the number of ambassadors has multiplied as the number of independent states has increased, Hungary still fares the worst, with $95 \%$ of its ambassadors male. The Czech Republic with a high proportion of male ambassadors at $85 \%$ is the closest to parity, while $90 \%$ of Poland and Slovakia's embassies are led by men. (Compare to Norway this at $64 \%$, which itself is still far from its stated and propagated goal of parity.) In key diplomatic positions, namely the EU, Germany, the US, Great Britain and Russia, at most one woman represents the V4. 
The percentages may be misleading, because the research focuses on a small group within which the appointment of a female Minister of Foreign Affairs would considerably shift the percentages. Still, the numbers demonstrate that the situation differs greatly from other prestigious professions and from other countries, such as the Scandinavian states. I analyse the reasons for this below.

\section{The reasons}

International diplomacy was considered a man's realm in the Visegrad countries, remaining so after 1989. Surveying the reasons of this phenomenon is the first step towards achieving potential change.

Women gain space very slowly in politics, especially when it comes to institutional leadership There are still many of the opinion that women should focus on areas suited for women, that is: social affairs, education and culture. This rhetoric places foreign affairs and its sometimes merciless representation of interests among "hard" issues like military affairs, which is obviously "no country for women" according to the Visegrad Four. It gets conflated with the prejudiced supposition that women as a whole are peaceloving, rejecting the use of force. If women were to behave accordingly, they would fulfill these imaginary expectations, and as a result reduce their professional capacity to maneuver in diplomacy.

The nature of the work in international diplomacy necessitates long and continuous education. Women presently encounter educational disadvantages as in many other professions, because of the difficulties of balancing work and childcare. Positing the issue in this manner is inherently discriminative because why would only women - and not men - have to juggle family and work? The four ambassadors (and their few female successors) solved this problem as early as the 1920s. Being a female ambassador certainly represents a privileged position in itself. However, it is also true, that if the duties of childcare oblige a female diplomat to leave temporarily her trade, her peers will accomplish most of their professional training and tasks ensuring their professional advancement, whereas in the best-case scenario, the female diplomat would return to her same or equivalent position in the rigid hierarchy whence she had departed.

The other argument against appointing women in leading diplomatic positions relates to the schedule of work. The reconciliation of family life and work is especially demanding for 
women in diplomatic careers. As in many other professions such as laboratory research, a dipomat's working hours are not limited to an eight hours standard. In international diplomacy a workday goes from morning until late evening, sometimes each evening with multiple events.

The diplomatic service in itself is strictly hierarchical, because an embassy has many employees from accountant to military attaché, but there is only one ambassador, whose opinion really matters and who officially represents their country's "opinion." In leadership theory a general doubt is cast on whether women are suitable for leadership at all. In past decades such doubt has been overcome in luckier parts of the world. The four "first" female ambassadors demonstrate that indeed women are qualified for leadership positions such as the oversight of an embassy. Women's exclusion due to stereotypes and structural inequality is utterly antidemocratic. The person of the ambassador is part of the state's image. In American diplomacy experts in foreign affairs do their jobs while ambassadors mainly have representative tasks, conveying messages already cleared by the expert body.

Twenty-five years after the change of the regime and still norms that would sanction sexism against women did not change. Former Hungarian Minister of Foreign Affairs and tenured CEU professor Péter Balázs in an interview given to critical political weekly Magyar Narancs (24 September 2015) said that: "If a woman says no, it means: perhaps. If she says perhaps, it means: yes. If she says yes, she is not a real woman. Now if a diplomat says yes, it means: perhaps. If he says perhaps, it means: no. And if he says no, then he is not a real diplomat." This quote exemplifies the kinds of obstacles women face when choosing a diplomatic career.

\section{Why is it at all a question if there is an absence of women in international diplomacy?}

The most commonly used view of positions with great prestige and power is that they are filled on a "merit base." The best one gets appointed. As demonstrated in the previous section, because women start with a load of structural disadvantages, the "merit based" appointments merely perpetuate existing structures.

The first notion that brings attention to the dearth of women in diplomacy, is the principle of democracy. It is not democratic if a group is excluded from a profession. Despite all the mystification that surrounds it, international diplomacy is a profession like any other, but with great prestige, high status and compensation. However, there is a surprising argument, applied to 
support the inclusion of women. According to this women have different skills, thus relating to men in a complementary, supplementary role, as they are kinder, more cooperative, and more ready to avoid conflict. Equally deployed by some feminists, the argument that women should be involved in greater numbers into the diplomatic service exactly because of these "complementary" features is especially dangerous as it assumes that all women possess the same characteristic traits (non-confrontationality, empathy, cooperativeness etc.), as if they were biologically determined. Moreover, this puts under question the democratic principle that each person has the right to perform the work they wish to perform, because the principle of equal chance is not fulfilled.

\section{Possible change?}

What would change this sorrowful image represented by the V4's latest survey? Until now successors of the four "first" female ambassadors are few. The diplomatic service, despite the equalizing politics of state-appropriated feminism, remained a male profession. According to the above quoted research the percentage of female ambassadors was less than 1\% between 1975 and 1989 in Polish, Hungarian and Czechoslovakian foreign affairs. For decades scarcely was a woman appointed as an ambassador. Ambassadorial positions which represent the peak of diplomacy remained men's privilege after 1989 as well.

If one follows the "merit based" argumentation, we cannot expect much change in the forthcoming period either, because social differences are continuously increasing. The "neoliberal neopatriarchal order" works via preserving the secondary status of women, as exemplified by the above-quoted interview with the former Minister of Foreign Affairs Balázs. Still there are means to change the situation. Firstly there are the international conventions and their observance. Such is the CEDAW report which systematically requests numeric data from the countries on how many women have public positions, diplomacy included. The second is deliberate recruitment of women for diplomatic service, which is a step towards the quota, but for that it should be admitted that specific support institutions and provisions are necessary. In Scandinavian countries change happened with the introduction of the quota, which aimed at combatting structural disadvantages. The first step towards the introduction and ratification of quotas is making inequality visible. That necessitates inner political change, which in one of the Visegrad countries has already started. The rude awakening of women at the 2009 Polish 
commemoration of the 1989 events in understanding that they were posteriorly erased from its history, and the Solidarity movement, played a great role in the success of the Polish parliamentary quota. This gave women the courage to organize and institutionalize themselves so well that the Polish Women's Congress not only became a political factor that could not be sidestepped in policy issues, but achieved the legally regulated 35\% quota on the party lists at the elections. Of course, it will take time until this change of approach reaches the level of policy making. In Hungary, the left-appointed, all-male Bajnai-government (2009-2010) introduced a program to facilitate employment of people of Roma origin in government agencies, among them the foreign affairs service. From the original one hundred participating youth, today less than ten remain within the Hungarian state apparatus, which has undertaken multifold restructurings since. This short example emphasizes how policy tools can bring long term solutions only if the political will is consistently present, and only if the initiation is supported and monitored, which in this case ceased to happen after the 2010 change of the government.

The international and civil organizations of national and international ranks are campaigning for a change of norms. However, the change of norms should spread into the work culture and into issues important for women. Instead of separating and isolating so-called women's issues such as the social, educational and cultural affairs, gender equality should be present in all policy making. This concerns everything from diplomatic recruitment to diplomatic policies which affect women. Nevertheless, the change of norms is fruitful only if accompanied by a change of habits on an individual level. When in 2006 I was the Hungarian government's CEDAW candidate, the frequently posited question during introductory interviews was whether I have a husband and child, as if my suitability to represent women's equal opportunities was dependent upon my family status. It was not. Nor was it in the case of the four "first" female ambassadors either. For the change of such habits mentor programs offer support. Those who participate in the program get in via an application, and within the program they can consult more experienced colleagues from their field. Informal mentoring has always been part of the process of selecting a successor. It is not by mistake that it is women who gain from such a formalized program, because informal selection favors young men who already have their networks. These mentoring programs represent institutional commitment to the systematic battle against structural disadvantages, and they also render inequalities visible. The question concerning mentor 
programs is how they can achieve successful institutional change and not merely albeit laudably cultivate the skills (negotiation skills, communication training, etc.) of particular individuals.

\section{Conclusion}

The latest comparative analysis of the Visegrad countries' diplomacy reveals that little has changed in women's representation in diplomatic leadership since the time of the first four female ambassadors, key positions are mainly filled by men. The rhetoric which emphasizes women's complementary role causes more harm than representing real structural change. Abgar, Chodakauskaite, Schwimmer and Kollontai were leaders in international diplomacy because of who they were as people and because of the social transformations of their era. Today in many countries the norms and values attached to women's participation in diplomacy have undertaken a transformation. At the same time, the anti-gender movement has emerged in opposition to the human rights framework. This movement questions whether the differences between the situation of women and men are social, evoking instead the argument of biological determinism. Abgar, Schwimmer, Chodakauskaite and Kollontai's successors therefore have twice as difficult a role. The changes that have started in the Visegrad countries, although they will not transform diplomatic institutions fundamentally, may be fruitful in the long run. All this in the midst of the attacks of a new counter-movement, which once again attempts to perpetuate structural inequality by asseverating "merits." 